\title{
Single step synthesis and characterization of Silver nanoparticles from Ocimum tenuiflorum L. Green and Purple.
}

\author{
Anuradha. $G^{1}$, B. Syama Sundar* ${ }^{1}$, M. V. Ramana ${ }^{2}$ J. Sreekanth kumar $^{3}$ and \\ T. sujatha ${ }^{4}$ \\ ${ }^{1 .}$ Department of Chemistry, Acharya Nagarjuna University, Guntur, A.P.India \\ * Present position: Vice-Chancellor, Yogi Vemana University, Kadapa, A.P. India. \\ 2. Department of Physics, SR\&BGNR Govt. Arts \& Science College, Khammam, A.P.India. \\ ${ }^{3 .}$ Department of H\&S Swarna Bharathi Institute of Science and Technology, Khammam, A.P.India. \\ 4. Department of Microbiology SR\&BGNR Govt. Arts \& Science College, Khammam, A.P.India.
}

\begin{abstract}
A single step environnemental friendly approach is employed to synthesise Silver nanoparticles using Ocimum tenuiflorum L. green and purple (Tulasi) varieties. Synthesised AgNps are analysed by using UVVisible, FTIR, Scanning Electron Microscope (SEM) and Energy Dispersive X-ray spectroscope(EDX). The formation of nanoparticles was confirmed by colour change and the surface Plasmon absorption band was measured by the UV-Visible spectroscopy. The FTIR peak corresponds to the presence of $C$-H vibration of the aromatic ring and the stretch vibration of $C$-O indicates carbonyl group and flavonoids. SEM analysis of the synthesised Silver nanoparticles are clearly distinguishable and the particles are measured <100nm in size. The EDX spectra show the purity of the material. Synthesis is conventional and found to be efficient in terms of reaction time as well as cost effective.
\end{abstract}

Keywords : Ocimum tenuiflorum, EDX, SEM analysis, Silver nano particles.

\section{Introduction}

Nanotechnology is a rapidly expanding and potentially beneficial field with tremendous implications for society, industry, and medicine. The uses of nano-sized particles are even more remarkable. They are mostly prepared from noble metals like silver, gold, platinum and palladium. Silver nanoparticles being most exploited [1]. They find applications in various fields like medicine, electronics, textile, cosmetics, and so forth. Biological methods have emerged as an alternative to the conventional methods for synthesis of nanoparticles. Synthesis of inorganic nanoparticles by biological systems makes nanoparticles more biocompatible and environmentally benign [2]. Numerous microorganisms and plant extracts have been applied to synthesize inorganic nanostructures either intracellular or extracellular $[3,4,5]$. Synthesis of silver nanoparticles by using various Ocimum species such as O.canum [6], O.basilicum [7], O.sanctum [8] and O.grattissimum [9] have been reported, the potential of the plant for the formation of silver nanoparticles is yet to be fully explored. Gold [10] and copper [11] nanoparticles are reported from O. sanctum. They also exhibit wide range of therapeutic effects like antibacterial, anti fungal and anti oxidant activities.

Here, we report an inexpensive, eco-friendly, rapid synthesis of silver nanoparticles by reduction process using leaf extracts of Ocimum tenuliflorum L. Green (Fig.1) and Ocimum tenuliflorum L. Purple (Fig.2) plants. The plant extract, which can act both as reducing and stabilizing agent. Ocimum tenuliflorum L. is a member of Lamiaceae family consists of almost 200 species of herbs and shrubs [12, 13] and is graded high among some of the astonishing herbs for having tremendous medicinal potentialities. There are large numbers of distinct species and varieties falls in this genus [14, 15]. It is widespread over Asia, Africa, Central and Southern America [16]

There are two kinds of Ocimum sanctum/ tenuliflorum available, in Telugu Purple variety is called Krishna Tulsi and Green variety is called Sri Tulsi and the common name is Holy basil. The more exuberantly flavored purple holy basil has dark green leaves with reddish purple stems and a purplish cast on the younger leaves known as Krishna Tulsi, while the milder green variety has medium green leaves with very light green, almost white stems known as Sri Tulsi, their chemical constituents are similar, and also have common medicinal properties [17]. The stem and leaves of holy basil contain a variety of constituents that may have biological activity, including saponins, flavonoids, triterpenoids and tannins. The leaf volatile oil contains eugenol, euginal (also called eugenic acid), urosolic acid, carvacrol, linalool, limatrol, caryophyllene, methyl carvicol, luteolin, vitexin, isovitexin, orientin, isoorientin, aesculin, chlorogenic acid, aesculetin, caffeic acid, betacarotene, rosmarinic acid, apigenin, cirsimaritin, isothymusin , isothymonin, orientin, vicenin, ascorbic acid and carotene are also reported[17,18]. Tulsi plant is known to possess therapeutic potentials and have been used by traditional medical practitioners as analgesic, anticancer, antiasthmatic, antiemetic, diaphoretic, antidiabetic, antifertility, 
hepatoprotective, hypotensive, antistress, anti-hyperlipidemic, antioxidant potentials in experimental animals [19-21].

Ocimum tenuliflorum L. Green (Fig.1) and Ocimum tenuliflorum L. Purple (Fig.2) plants were collected from university campus Acharya Nagarjuna University, Guntur, Andhra Pradesh and identified by the Department of Botany, Kakatiya University, Warangal, A.P.India and further the herbarium sheets were preserved in the Department as a record.

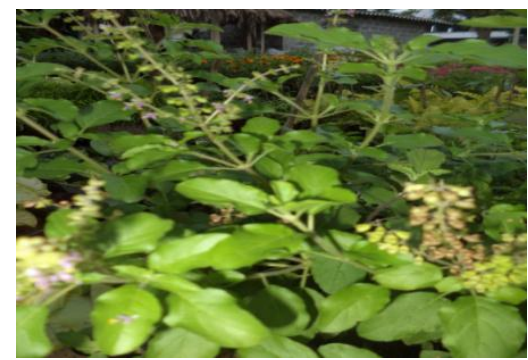

Fig.1 Ocimum tenuiflorum. L Green (Sri Tulasi)

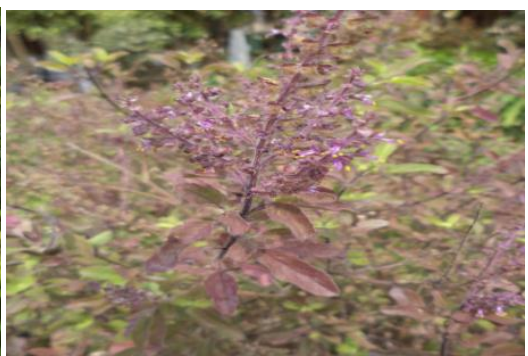

Fig.2 Ocimum tenuiflorum. L Purple (Krishna Tulasi)

\section{1 Preparation of leaf extract}

\section{Materials and methods}

Fresh leaves were washed several times with tap water and later with deionised water. 10 gram of washed fine cut leaves along with $100 \mathrm{ml}$ double distilled water were taken in $250 \mathrm{ml}$ glass beaker and boiled for 5 minutes at $80^{\circ} \mathrm{c}$. The extract was cooled to room temperature and filtered with Whatman No 1 filter paper. The filtrate was centrifuged for 10 minutes at $10000 \mathrm{rpm}$, the supernatant was collected and stored at $4^{\circ} \mathrm{C}$. O.tenuliflorum L. Green and O.tenuliflorum L. Purple leaf extracts were prepared similarly.

\section{2 Preparation of $1 \mathrm{mM} \mathrm{Ag} \mathrm{NO}_{3}$ solution}

Accurate concentration of $1 \mathrm{mM} \mathrm{AgNO}_{3}$ (Merck India Ltd) was prepared by dissolving 0.169 gram $\mathrm{AgNO}_{3}$ in $1000 \mathrm{ml}$ double distilled water and stored in Amber colored bottle to avoid auto oxidation of silver.

\section{3 Nano biosynthesis}

In the single step green synthesis, $5 \mathrm{ml}$ of leaf extract was added to $95 \mathrm{ml}$ of $1 \mathrm{mM}$ aqueous $\mathrm{AgNO}_{3}$ solution and heated up to $80^{\circ} \mathrm{C}$ for 5 minutes, the colour change was observed (Fig. $3 \& 4$ ), which stands as a preliminary identification of the formation of Silver nanoparticles. The Silver nanoparticles solutions thus obtained were purified by repeated centrifugation at $10000 \mathrm{rpm}$ for 15 minutes. The supernatant was transferred to a clean dry beaker for further settlement of particles and repeated centrifugation was carried using cooling microfuge to get dried Silver nanoparticles. The sample so obtained was dried in an incubator. The particles obtained were used for further characterization. In the same way O.tenuiflorum L. Green and O.tenuiflorum L. Purple leaf extract Silver nano particles were synthesized. Thus the Silver nanoparticles are synthesized in a single step green approach.

\section{Characterization}

Synthesized Silver nano particles were initially characterized by taking small aliquot of sample in to UV-Visible spectrophotometer absorption spectra at 300-700 nm using Shimadzu UV-1800 Spectrophotometer. Fourier-transform infra red spectroscopy Bruker model was used for the analysis of the reduced silver. The spectrum was recorded in mid-IR region of $400-4000 \mathrm{~cm}^{-1}$ with 16 scan speed, using attenuated total reflectance (ATR) technique.

Scanning electron microscopic (SEM) analysis was done using Zeiss, EV-18 model. A thin film of the sample was prepared on a carbon coated copper grid by placing small amount of the sample on the grid. Then the film on the SEM grid was allowed to dry using mercury lamp for $5 \mathrm{~min}$.

Energy Dispersive X-ray analysis (EDX) was carried out on Zeiss, EV-18 model. The peaks obtained from EDX gives the element composition of the sample.

\section{Results and Discussion}

Synthesis of Silver nanoparticles by using Biological materials is one of the most widely used methods for the synthesis of Silver colloids. The present study emphasizes the use of O.tenuiflorum L. Green and O.tenuiflorum L. Purple for the Synthesis of Silver nanoparticles leaf extract, which act as reducing and capping agents in silver nanoparticles synthesis. Studies have indicated that biomolecules like protein, phenols, and flavonoids not only play a role in reducing the ions to the nano size, but also play an important role in the capping of the nanoparticles [22, 23]. The reduction of $\mathrm{Ag}+$ ions by combinations of biomolecules found in 
these extracts such as vitamins, enzymes, proteins, amino acids, polysaccharides and organic acids [23, 24] which are environmentally benign, yet chemically complex.

\section{1. UV -Visible spectra analysis}

The nanoparticles were preliminarily characterized by UV-Visible Spectroscopy, which is proved to be a very useful technique for the analysis of nanoparticles. As the leaf extracts were mixed with the aqueous solution of the Silver ion complex it was changed from Yellow to red for O.tenuiflorum L. Green (Fig.4) and red to brown for O.tenuiflorum L. Purple (Fig.4) due to excitation of the surface plasma vibrations indicate the formation of the Silver nanoparticles [25]. UV-Visible Spectrograph of Silver nanoparticles has been recorded as a function of time by using quartz cuvette with distilled water as the reference. The reaction between $95 \mathrm{ml}$ Silver nitrate solution and $5 \mathrm{ml}$ leaf extract was carried at $90{ }^{\circ} \mathrm{C}$. The UV spectrum absorption is recorded at 427nm (Fig.3) and 432nm (Fig.4) for O.tenuiflorum L. Green and O.tenuiflorum L. Purple respectively.

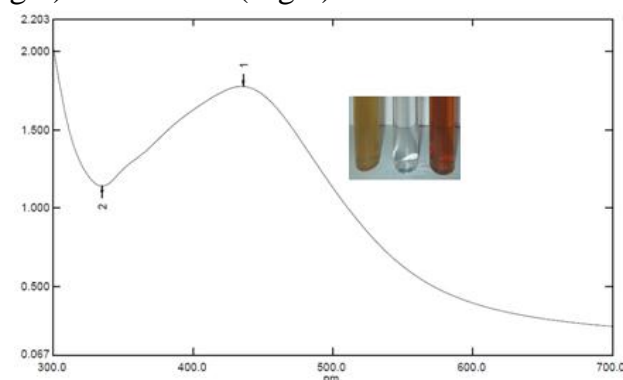

Fig.3 UV spectrum absorption of AgNps formed from O.tenuiflorum L. Green

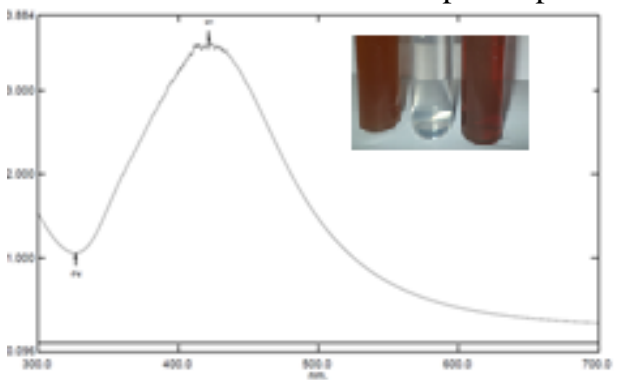

Fig .4 UV spectrum absorption of AgNps formed from O. tenuiflorum L. Purple

\subsection{FTIR- Spectroscopy}

The bands obtained from both the varieties are almost same with small variations at absorbed wavelengths and percentage transmittance.

The FTIR spectrum of silver nanoparticles from O.tenuiflorum L. Green are shown in Fig.5 The band at $3300 \mathrm{~cm}^{-1}$ is assigned to the $\mathrm{O}-\mathrm{H}$ stretching of $\mathrm{H}$-bonded alcohols and phenols. The band at $2924 \mathrm{~cm}^{-1}$ is attributed to $\mathrm{O}-\mathrm{H}$ stretching of carboxylic acids. The band at $1644 \mathrm{~cm}^{-1}$ corresponds to the $\mathrm{N}-\mathrm{H}$ bending of primary amines. The bands at $1447 \mathrm{~cm}^{-1}$ are related to the $\mathrm{C}-\mathrm{C}$ stretching of aromatic ring structure and the charecteristic peak at $1369 \mathrm{~cm}^{-1}$ are related to the $\mathrm{C}-\mathrm{N}$ streching of aromatic amine group. Whereas in the region 1221-1021 $\mathrm{cm}^{-1}$ are corresponding to the C-C streching of alcohols carboxylic acids, ethers and esters.

The FTIR spectrum of silver nanoparticles from O.tenuiflorum L. Purple is shown in Fig.6. The band at $3296 \mathrm{~cm}^{-1}$ is assigned to the O-H stretching of H-bonded alcohols and phenols. The band at 2931 $\mathrm{cm}^{-1}$ is attributed to $\mathrm{O}-\mathrm{H}$ stretching of carboxylic acids. The band at $1643 \mathrm{~cm}^{-1}, 1541 \mathrm{~cm}^{-1}$ corresponds to the N$\mathrm{H}$ bending of primary amines. The bands at $1446 \mathrm{~cm}^{-1}$ are related to the $\mathrm{C}-\mathrm{C}$ stretching of aromatic ring structure and the peak at $1369 \mathrm{~cm}^{-1}$ are related to the $\mathrm{C}-\mathrm{N}$ streching of aromatic amine group. Whereas in the region 1221-1035 $\mathrm{cm}^{-1}$ are corresponding to the $\mathrm{C}-\mathrm{C}$ streching of alcohols, carboxylic acids, ethers and esters are confirmed. In the present study, the peaks are more charecteristic of eugenol, linalool and flavanoids.

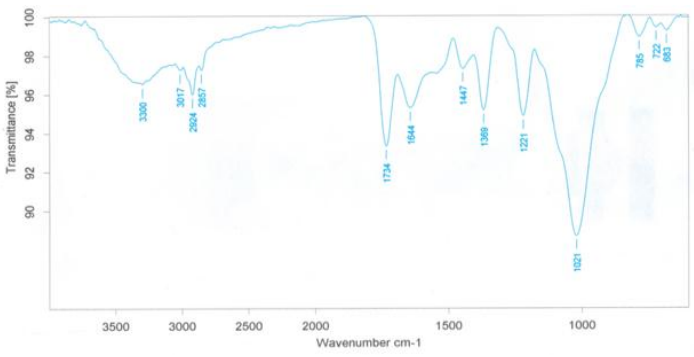

Fig.5 FTIR spectrum of AgNps formed from O.tenuiflorum L. Green

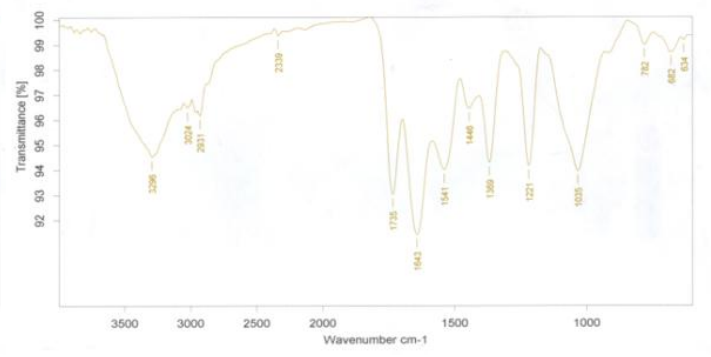

Fig .6 FTIR spectrum of AgNps formed from O. tenuiflorum L. Purple

\subsection{SEM Analysis}

The SEM images shows high density Silver nanoparticles synthesized by the leaf extract, further confirmed the development of silver nano structure. The SEM image shows the formation of porous surface with spherical nano particles and flake surfaced spherical nano particles in O.tenuiflorum L. Green and O.tenuiflorum L. Purple respectively. They were clearly distinguishable and range between 30.56-82.63 nm for O.tenuiflorum L. Green (Fig.7) and 38.95-53.47 nm for O.tenuiflorum L. Purple (Fig.8). 


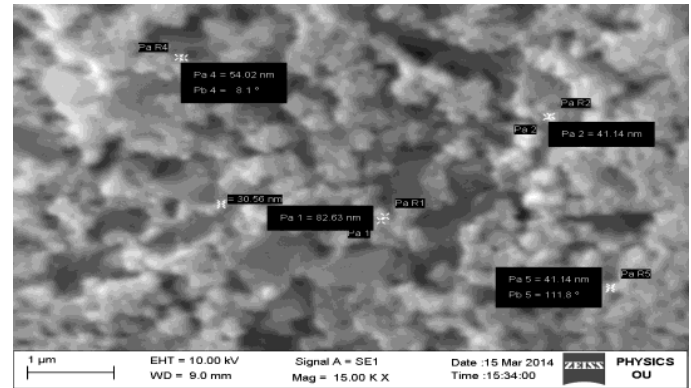

Fig .7 SEM image of silver nanoparticles formed from O.tenuiflorum L. Green

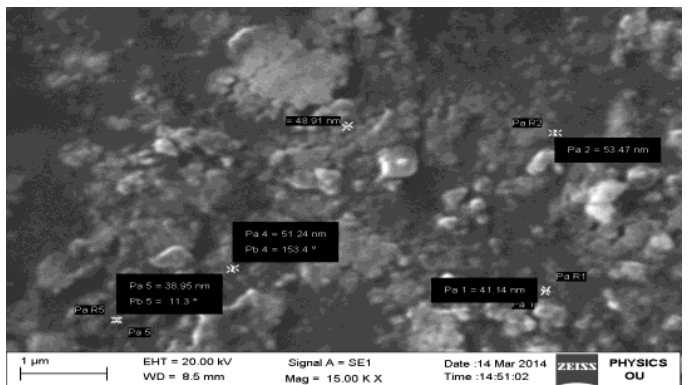

Fig .8 SEM image of silver nanoparticles formed from O.tenuiflorum L. Purple

\subsection{EDX Analysis}

The EDX spectra show the purity of the material and the complete chemical composition of synthesized silver nanoparticles. In the present synthesis EDX analysis shows that the samples of Silver nanoparticles produced by O.tenuiflorum L. Green (Fig.9) and O.tenuiflorum L. Purple (Fig.10) are 93.5\% and 98.5\% respectively. It revealed high percentage of silver which indicate the purity of the synthesized sample.

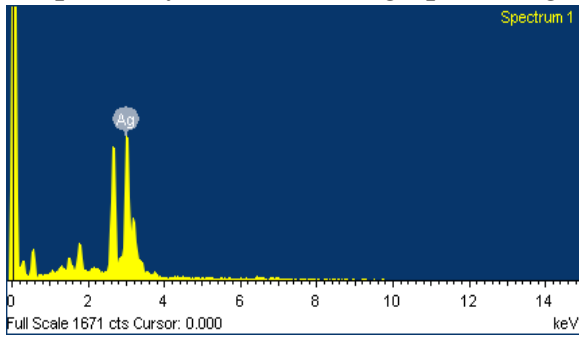

Fig .9EDX images of silver nanoparticles produced from O.tenuiflorum L.Green

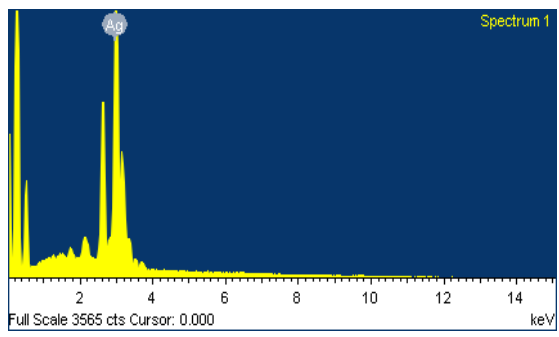

Fig .10 EDX images of silver nanoparticles produced from O.tenuiflorum L.Purple

\section{Conclusion}

The present study reveals that the two plant species O.tenuiflorum L. Green and O.tenuiflorum L. Purple are good source for the synthesis of Silver nanoparticles at a faster rate. The formation of silver nanoparticles was confirmed by the colour change within 30 minutes. The bioreduced silver nanoparticles were characterized using UV-Vis, SEM, FTIR techniques. The Ag NPs formed were quite stable in the solution. The carbohydrates, flavanoids and poly phenol constituents present in leaf extract act as the surface active stabilizing molecules for the synthesis of Ag NPs. The method was unique, cost effective to biosynthesize nanoparticles from the natural resources. Still more clinical trials need to be conducted to support its therapeutic uses.

\section{Acknowledgements}

The authors wish to acknowledge the Department of Physics, Osmania University, Hyderabad for SEM, EDX and CFRD, OU, for FTIR spectral analysis. The authors are thankful to the Department of Botany, Kakatiya University, Warangal, A.P.India for the identification of plant species.

\section{References}

[1]. N. Roy and A. Barik, Green synthesis of silver nanoparticles from the unexploited weed resources, International Journal of Nanotechnology, vol. 4, 2010, 95.

[2]. K. Govindaraju, S. Tamilselvan, V. Kiruthiga, and G. Singaravelu,Biogenic silver nanoparticles by Solanum torvum and their promising antimicrobial activity, Journal of Biopesticides,vol. 3, no. 1, 2010, 394-399.

[3]. A.B Bazylinski and B.R. Frankel, Magnetosome formation in Procayotes,Nature reviews-Microbiology. 2, $2004,213-230$.

[4]. F.M. Lengke E.M Fleet, G. Southam, Biosynthesis of silver nanoparticles by filamentous cyanobacteria a from a silver (I) nitrate complex, Langmuir. 23, 2007, 2694- 2699.

[5]. V.Parashar, R. Prashar, B. Sharma, \& A.C. Pandey, Parthenium leaf extracts Mediated synthesis of silver nanoparticles: a novel approach towards weed utilization, Digest journal of nanomaterials and biostructures. 4(1), 2009, 45-50.

[6]. Chidambaram Jayaseelan,Abdul Abdul Rahuman,Acaricidal efficacy of synthesized silver nanoparticles using aqueous leaf extract of Ocimum canum against Hyalomma anatolicum anatolicum andHyalomma marginatum isaaci(Acari:Ixodidae),Parasitology research, 111,(3),2012, 1369-78

[7]. K.sivaranjani and M.Meenakshisundaram,Biological synthesis of silver nanoparticles using Ocimum basillicum leaf extract and their antimicrobial activity, International research Journal of Pharmacy, 4(1),2013, 225-29.

[8]. Daizy Philip,c.Unni,Extracellular biosynthesis of gold and silver nanoparticles using Krishna Tulasi(Ocimum sanctum)leaf, Physica e:Low-dimensional Systems and Nanostructures, 43,(7),2011, ,1318-22 
[9]. T.tejaswi,K.venkateswara Rao,Ch.Shilpa Chakara,Silver Nanoparticles synthesis and stabilization for its Antimicrobial Activity,International Journal of current Engineering and Technology,3,( 2),2013,501-506.

[10]. Paul Koushik and *Bag Braja Gopal Ocimum sanctum (Tulasi) Stem Extract Mediated Size Controlled Green Synthesis of Polyshaped Gold Nanoparticles and Its Application in Catalysis, Int. J. Res. Chem. Environ. 3 (2), 2013, 128-135.

[11]. P. S. kulkarnia , K. K. Jareb, S. B. Kadlagb,R. M. Chaudharib, V. D. Kulkarnib, Green synthesis of copper nanoparticles using Ocimum sanctum leaf extract, Indian Streams Research Journal,2013,1-5.

[12]. Charles, D.J. and J.E. Simon, 1990. Comparison of extraction methods for the rapid determination of essential oil content and composition of basil. J.Amer. Soc. Hort. Sci., 115, 2013, 458-462.

[13]. Mondello, L., G. Zappia, A. Cotroneo, I. Bonaccorsi, J.U. Chowdhury, M. Yusuf and G. Dugo, Studies on the essential oil-bearing plants of Bangladesh. Part VIII. Composition of some Ocimum oils O.basilicum L.var.purpurascences;O.sanctum L.green, O. sanctum L. purple, O. americanum L. citral type; O.americanum L. camphor type. Flavour and Fragrance J., 17, 2002 , 335-340.

[14]. Labra, M., M. Miele, B. Ledda, F. Grassi,M. Mazzei and L.F. Sala, Morphological characterization, essential oil composition and DNA genotyping of Ocimum basilicum cultivars. Plant Sci., 167, 2004, 725-731.

[15]. Klima'nkova, E., K. Holadová, J. Hajšslová, T. Ėajka,J. Poustka and M. Koudela, Aroma profiles of five basil (Ocimum basilicum L.) cultivars grown under conventional and organic conditions. Food Chemistry, 107, 2008, 464-472.

[16]. S. Mondal, B. R. Mirdha, and S. C. Mahapatra, "The science behind sacredness of Tulsi (Ocimum sanctum linn.)," Indian Journal of Physiology and Pharmacology, 53, (4), 2009 291-306.

[17]. M.Rama and B.Syama sundar ,Phytochemical constituents and antioxidant activity of extract from the leaves of Ocimum sanctum Green and Purple,International Journal of Chemical and Pharmaceutical Research,2(2),2013, 55-64.

[18]. Sonia Verma,Preeti Kothiyal,Pharmacological activities of different species of Tulasi, International Journal of Biopharma \& Phytochemical Research, 1(1), 2012, 21-39.

[19]. Shahedur Rahman, Rezuanul Islam, M. Kamruzzaman, Khasrul Alam and Abu Rena Mastofa Jamal, Ocimum sanctum L.: A Review of Phytochemical and Pharmacological Profile, American Journal of Drug Discovery and Development, 2011, 1-15.

[20]. S.Sethi,Om.Prakash,M.Chandra etal,Antifungal activity of essential oils of Ocimum species collected from different locations of Uttarakhand,Indian Journal of Natural Products and Resources, 4(4), 2013, 392-397.

[21]. Charusheela Ramteke, Tapan Chakrabarti, Bijaya Ketan Sarangi, and Ram-Avatar Pandey, Synthesis of Silver Nanoparticles from the Aqueous Extract of Leaves of Ocimum sanctum for Enhanced Antibacterial Activity, Journal of Chemistry ,2013, 1-7

[22]. A. Vedpriya,Living Systems: eco-friendly nanofactories, Digest Journal of Nanomaterials and Biostructures, 5,(1), $2010,9-21$.

[23]. O. Collera-Z 'úniga, F. Garc'1a Jim'enez, and R. Mel'endez Gordillo, Comparative study of carotenoid composition in three mexican varieties of Capsicum annuum L,Food Chemistry,90, (1-2), 2005,109-114.

[24]. B. H. Jagadeesh, T. N. Prabha, and K. Srinivasan,Improved shelf life of bell capsicum fruits by manipulation of the activities of glycosidases through heat,Indian Journal of Plant Physiology, 9,(2 ), 2004,164-168.

[25]. S. S. Shankar, A. Rai, B. Ankamwar, A. Singh, A. Ahmad, and M. Sastry,Biological synthesis of triangular gold nanoprisms, Nature Materials.3, 2004,482-488. 